\title{
Effect of surface sizing on the surface chemistry of paper containing eucalyptus pulp
}

\author{
Isabel Maria Teixeira Moutinho ${ }^{1, *}$, Anne \\ Marjatta Kleen², Maria Margarida Lopes \\ Figueiredo $^{1}$ and Paulo Jorge Tavares Ferreira ${ }^{1}$ \\ ${ }^{1}$ Departamento de Engenharia Química, Universidade \\ de Coimbra, Coimbra, Portugal \\ ${ }^{2}$ KCL, Tekniikantie 2, 02150 Espoo, Finland \\ ${ }^{*}$ Corresponding author. \\ Departamento de Engenharia Química, Universidade \\ de Coimbra, Pólo II - Pinhal de Marrocos, 3030-290 \\ Coimbra, Portugal \\ Phone: +351-239-798-700 \\ Fax: +351-239-798-703 \\ E-mail: isamim@gmail.com
}

\begin{abstract}
The effect of different surface sizing formulations on the chemical features of surfaces of the papers produced from Eucalyptus kraft pulp was studied. The surface analysis techniques, electron spectroscopy for chemical analysis and time-of-flight secondary ion mass spectrometry were applied. An uncoated base paper, the reference material, was sized with blends of cationic starch with either co-acrylonitrile-acrylate or co-styrene-acrylate. The results of both techniques are in good agreement and complete each other. It was possible not only to detect the presence of the surface sizing agents on the paper surface but also to distinguish them and evaluate their distribution and relative concentration. In addition, it was found that application of higher amounts of the sizing formulations, at a constant ratio of $20 \%$ copolymer to starch, did not significantly change the chemical properties of the paper surfaces.
\end{abstract}

Keywords: electron spectroscopy for chemical analysis (ESCA); Eucalyptus globulus; kraft pulp; surface chemistry; surface properties; surface sizing; time-of-flight secondary ion mass spectrometry (ToF-SIMS).

\section{Introduction}

The papermaking industry has to increase its know-how and improve the quality of all paper grades (COST E32 2002; Pruszynski 2003) due to the increasing demands of customers and the competition between information media. For printing and writing papers and other special paper grades, physical and chemical properties of paper surfaces are critical for achieving a good performance of the final products (Carceller and Juppo 2004; Laleg 2004; Lertsutthiwong et al. 2004). The physical structure of the paper surface - its roughness and porosity, for example - plays an important role on the quality of the printed details. The surface is influenced by the structural and surface characteristics of the fibers, fines, and mineral fillers of the paper matrix. Moreover, the surface chemistry of paper has a great impact on the spreading and absorption rate of coating colors and inks. The surface characteristics of papers depend on the base paper composition and on the surface treatments, such as coating and surface sizing (Keskitalo 2000; Rutar and Hladnik 2000; Oliver et al. 2001; Koskela and Hormi 2003).

Surface sizing influences the porosity, roughness, internal strength of the paper, particles detachment, and the hydrophobic character of surface. The latter is important to prevent excessive absorption of liquids. Starch and synthetic polymers are common sizing chemicals and these also have an influence on the physical and chemical properties of paper bulk (Koskela and Hormi 2003; Pruszynski 2003; Laleg 2004; Lertsutthiwong et al. 2004; Mešic et al. 2004; Moutinho et al. 2007).

The characterization of paper surfaces is of outermost importance for evaluating the effect of sizing and selecting the most appropriate chemicals for a specific base paper (Donigian et al. 1997; Forsström et al. 2003; Hladnik 2003; Shirazi et al. 2003; Ajerschi et al. 2004; Carceller and Juppo 2004; Lertsutthiwong et al. 2004; Mešic et al. 2004; Hamers et al. 2005).

From the techniques currently available for chemical characterization of paper surfaces, the two most capable techniques were selected for this study. These are: 1) electron spectroscopy for chemical analysis (ESCA), and 2) time-of-flight secondary ion mass spectrometry (ToFSIMS). Since the fundamentals of these techniques are well described in the literature, only a short description of each technique is provided in this paper.

ESCA has been proved to be a sensitive technique for obtaining information about the chemical composition and structure of a solid surface, within a sampling depth of approximately $5 \mathrm{~nm}$ (Dorris and Gray 1978; Brinen, 1993; Kleen et al. 2003; Kangas and Kleen 2004; Hale et al. 2007). It is based on the energy changes of the emitted electrons to generate a spectrum of peaks corresponding to the elements present on the surface (except hydrogen and helium). The peak areas give measures of the relative amounts of each element (absolute quantitative measurements are seldom feasible), whereas the shape and position of the peaks reflect the chemical environment of each element, namely their bonding structure (Dorris and Gray 1978; Brinen 1993; Ström et al. 1993; Kleen et al. 2003; Kangas and Kleen 2004; Hale et al. 2007).

ToF-SIMS analysis provides additional information regarding the identification of not only elements but also molecular species present on the surface. The distribution of molecules at the surface can be deduced from the data, also as a function of depth at a submicron scale. This technique is suited for comparison of samples 
as it delivers semi-quantitative information of the surface constituents (Kleen 2000a,b, 2005; Kristola 2001; Kangas and Kleen 2004; Lee et al. 2006; Parolis et al. 2007). ToFSIMS is based on ionized particles which are emitted from a solid surface when energetic primary particles bombard that surface. The secondary ions are accelerated into a mass spectrometer, where they are analyzed by measuring their time-of-flight between the sample and the detector. Major compounds in mixtures can be separated. The mass range and resolution of the technique are high. The analyzed area in ToF-SIMS is smaller than that of ESCA, and the surface sensitivity is higher, because ToF-SIMS analyzes the outermost surface layers of 1-2 $\mathrm{nm}$.

There is a large body of literature concerning paper analysis by ESCA (Dorris and Gray 1978; Kleen et al. 2002; Shchukarev et al. 2003; Johansson et al. 2005; Freire et al. 2006) or by ToF-SIMS (Brinen and Proverb 1991; Fardim and Holmbom 2005a,b; Kleen 2000a,b, 2005), or both ESCA and ToF-SIMS (Brinen 1993; Kleen et al. 2003; Kangas and Kleen 2004).
The present work aims at obtaining detailed information about the chemical composition of the outermost surface layers of the surface sized papers and at answering the question how those surface layers are affected by the surface sizing formulations.

\section{Experimental}

\section{Paper samples}

A calendered uncoated base paper $\left(80 \mathrm{~g} \mathrm{~m}^{-2}\right)$ produced from bleached Eucalyptus globulus kraft pulp (ISO brightness $\approx 90$ ) and without any surface treatment was the reference paper (denoted as RP). This paper was surface sized with blends of cationic starch with either co-acrylonitrile-acrylate (samples A1 and A2) or co-styrene-acrylate (samples B1 and B2), as described in Table 1. The copolymers are schematically presented in Figure 1. Elemental analysis (Table 2): EA 1180 CHNSO from Fisons Instruments. Software: ChemSketch software. The cationic starch suspension is a commercial product supplied by the industry. Particle size measurement: COULTER N4 Plus Submicron Particle Sizer. Surface tension: OCA20 equip-

Table 1 Sample description.

\begin{tabular}{llcc}
\hline Sample & \multicolumn{1}{c}{$\begin{array}{c}\text { Surface sizing formulation } \\
\left(\% \mathrm{w} \mathrm{w}^{-1}\right)\end{array}$} & $\begin{array}{c}\text { Sizing amount } \\
\text { (pick-up) }\left(\mathrm{g} \mathrm{m}^{-2}\right)\end{array}$ & $\begin{array}{c}\mathrm{pH} \text { of the } \\
\text { sizing formulation }\end{array}$ \\
\hline RP (reference) & No surface treatment & 0.0 & $\mathrm{xxx}$ \\
A1 & 80\% of cationic starch & 3.5 & 5.07 \\
A2 & 20\% of co-acrylonitrile-acrylate & 9.0 & \\
B1 & $80 \%$ of cationic starch & 3.5 & 6.23 \\
B2 & 20\% of co-styrene-acrylate & 9.0 & \\
\hline
\end{tabular}

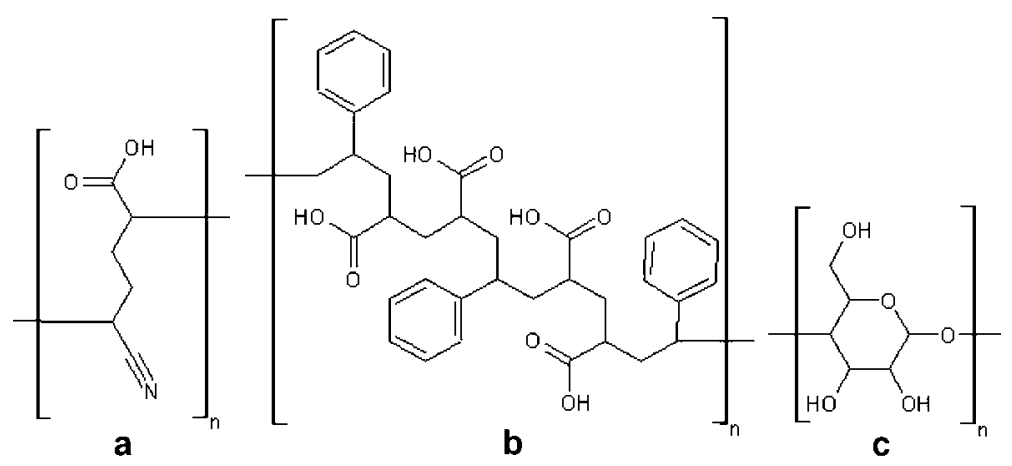

Figure 1 Schematic representation of the molecules used in the surface sizing formulations, computed using the software ChemSketch: (a) co-acrylonitrile-acrylate, (b) co-styrene-acrylate, (c) cationic starch.

Table 2 Properties of the compound in surface sizing formulations.

\begin{tabular}{|c|c|c|c|c|c|c|c|c|c|}
\hline \multirow[t]{2}{*}{ Compound } & \multirow{2}{*}{$\begin{array}{l}\text { Monomers } \\
\text { proportion }^{\text {a }}\end{array}$} & \multirow{2}{*}{$\begin{array}{l}\text { Solids } \\
\text { content } \\
(\%)\end{array}$} & \multirow[t]{2}{*}{$\mathrm{pH}$} & \multirow{2}{*}{$\begin{array}{c}\text { Particles } \\
\text { mean } \varnothing \\
(\mathrm{nm})^{\mathrm{b}}\end{array}$} & \multirow{2}{*}{ 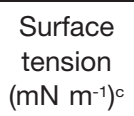 } & \multicolumn{4}{|c|}{ Amount $\left(\% \mathrm{w} \mathrm{w}^{-1}\right)$} \\
\hline & & & & & & $\mathrm{H}$ & $\mathrm{N}$ & $\mathrm{C}$ & $\mathrm{O}$ \\
\hline Cationic starch & - & 12.8 & 6.7 & 299 & 32.9 & 6.1 & 1.2 & 40.9 & 42.7 \\
\hline Co-acrylonitrile-acrylate & $1: 1$ & 35.2 & 3.4 & 254 & 47.6 & 7.6 & 11.6 & 61.4 & 19.5 \\
\hline Co-styrene-acrylate & $3: 4$ & 13.3 & 4.3 & 84 & 82.2 & 7.3 & 0.0 & 71.9 & 20.8 \\
\hline
\end{tabular}

aBased on elemental analysis (using the equipment EA $1180 \mathrm{CHNS}-\mathrm{O}$ from Fisons Instruments).

bDetermined using the COULTER N4 Plus Submicron Particle Sizer.

cMeasured with the OCA20 equipment form Dataphysics. 
ment from Dataphysics. Table 2 summarizes the most relevant information regarding the compound properties.

The surface sizing formulations were applied by a Mathis laboratory coating device (SVA-IR-B), which operates automatically with different velocities of the applicator roll. A $0.15-\mathrm{mm}$ diameter roll was used at a velocity of $6 \mathrm{~m} \mathrm{~min}^{-1}$. The total surface sizing pick-up was controlled by the weight applied on top of the applicator roll: in case of no weight, a $3.5 \pm 0.3 \mathrm{~g} \mathrm{~m}^{-2}$ pickup was obtained (samples A1 and B1), whereas by placing two weights of $730 \mathrm{~g}$ each on the applicator roll a $9.0 \pm 0.3 \mathrm{~g} \mathrm{~m}^{-2}$ pick-up was obtained (samples A2 and B2). The drying process was performed by an IR drier coupled to the applicator roll (1.0 kW drying intensity), followed by air drying (for at least $10 \mathrm{~min}$ ). The surface sized samples were calendered no further.

\section{Surface analyses}

ESCA analyses AXIS 165 high-resolution electron spectrometer, monochromatic Al K $\alpha$ irradiation $(12.5 \mathrm{kV}, 8 \mathrm{~mA})$. For each sample, survey scans in the range $0-1100 \mathrm{eV}(1 \mathrm{eV}$ step, $80 \mathrm{eV}$ analyzer pass energy) and high-resolution spectra of the $C 1$ region ( $0.1 \mathrm{eV}$ step, $20 \mathrm{eV}$ pass energy) were recorded at three different locations. The areas of the peaks corresponding to carbon (200-300 eV), calcium (350 eV), nitrogen (400 eV), oxygen (500-600 eV), and sodium (1000-1100 eV) were measured. The analyzed area was approximately $1 \mathrm{~mm}^{2}$ and the depth of analysis was $2-10 \mathrm{~nm}$. The sample surfaces were neutralized during the measurements with low-energy electrons.

ToF-SIMS measurements PHI TRIFT II time-of-flight secondary ion mass spectrometer. High mass resolution spectra and images in positive and negative ion modes were acquired by a ${ }^{69} \mathrm{Ga}^{+}$liquid metal ion gun with $15 \mathrm{keV}$ primary ions in bunched mode for mass spectra and with $25 \mathrm{keV}$ primary ions in unbunched mode for images over the mass range $2-2000 \mathrm{~m} \mathrm{z}^{-1}$. The primary ion current was $600 \mathrm{pA}$ and time per channel was 0.138 ns. The analysis area was $200 \times 200 \mu \mathrm{m}^{2}$ and the acquisition time was $2 \mathrm{~min}$ for spectra and $5 \mathrm{~min}$ for images. Analytical charge compensation was used for insulating samples. The calculated ion dose was $2.7 \times 10^{11} \mathrm{~cm}^{-2}$, which ensured static conditions during data acquisition. Three replicate runs were made for each sample. Selected peak areas were integrated from ToFSIMS spectra and normalized to the total ion intensity of the spectrum. Images were reconstructed from raw data files with the off-line WinCadence software.

\section{Results and discussion}

\section{Electron spectroscopy for chemical analysis (ESCA)}

The elements present at the paper surface can be identified from the survey scans obtained by ESCA. Figure 2 includes the results of the RP and of samples $A 1$ and $B 1$. The spectra of samples A2 and B2 corresponding to the largest amount of sizing agents are not shown, because they revealed only minor differences in the intensity of the peaks compared with samples A1 and B1, respectively.

The peaks corresponding to carbon, oxygen, and sodium can be easily detected in all the samples, whereas calcium is only visible in the RP and nitrogen in sample A1 (and A2). As readily visible, the most abundant elements are carbon and oxygen (hydrogen is not detectable by ESCA). For quantification, the amount of each element, relative to all specimens detected in the surface of each sample, was determined by measuring the peak area. The results, based on the analyses of three locations in each paper sample, are summarized in Figure 3 together with the reproducibility of the results. The reproducibility is satisfactory.

The amounts of carbon and calcium present at the surface of the RP are higher than those at the surface of the surface sized papers (Figure 3). The opposite is true for oxygen and sodium. The much larger amount of calcium detected in the RP is associated with the precipitated calcium carbonate applied as filler, which almost completely covered the surface after sizing. The same covering effect may be responsible for the slight decrease of the carbon percentage in the sized samples, while the proportion of oxygen is increased. The presence of $\mathrm{NaCl}$ in the cationic starch suspension (supplied by the industry) causes the increase of sodium at the surface of the sized papers, in comparison with the RP.

Although the co-styrene-acrylate polymer (B) contained approximately $1.5 \%$ more oxygen than the coacrylonitrile-acrylate polymer (A), similar amounts of oxygen were found on the surface of $A$ and $B$ sized papers (Figure $3 c$ ). This indicates that relatively more of the oxygen-rich starch and less copolymer were found on the A sized papers. Besides, though having a low surface tension, starch has large particles (Table 2), which leads to high surface concentrations. We suggest that copolymer A can penetrate easier into paper than copolymer B, which can be explained by its lower surface tension (Table 2). Finally, and as expected, the quantity of nitrogen increased significantly in samples A1 and A2 due to the presence of acrylonitrile copolymer.

It is obvious that no relevant benefits arise from increasing the surface sizing pick-up from 3.5 to $9.0 \mathrm{~g} \mathrm{~m}^{-2}$ since, in general, the differences between the RP and samples $A 1$ and $A 2$ are identical. The same is true for samples B1 and B2. Therefore, from a chemical point of view, a pick-up level of $3.5 \mathrm{~g} \mathrm{~m}^{-2}$ seems to be enough to promote the key changes intended by surface sizing.

The relative contents of the different "types" of carbon, considering their chemical environment and bonding structure, were determined from their high resolution spectra of carbon (Figure 4).

These results with a very good reproducibility are in agreement with the molecular structure of the sizing agents depicted in Figure 1. In fact, the relative amount of $\mathrm{C} 1$ is considerably higher for RP, especially in comparison with papers $A 1$ and $A 2$, probably mainly because of lower percentage of $\mathrm{C}=\mathrm{C}$ bonds in the sized papers. Acrylonitrile-acrylate copolymer (A), e.g., do not contain any $\mathrm{C}=\mathrm{C}$ bonds (Figure $1 \mathrm{a}$ ). It is also clear that, in terms of the type of different carbon bonds, there is a greater resemblance between samples $B 1$ and $B 2$ and the RP (Figure $4 a-c$ ) than between the latter and samples $A 1$ and $\mathrm{A} 2$. The exception occurs for the $\mathrm{O}-\mathrm{C}=\mathrm{O}$ bonds (C4, Figure $4 d$ ), which are predominant in the styreneacrylate copolymer (B1 and B2). This result is also supported by the results from elemental analysis demonstrating that the copolymer B contains more oxygen than the copolymer A. 

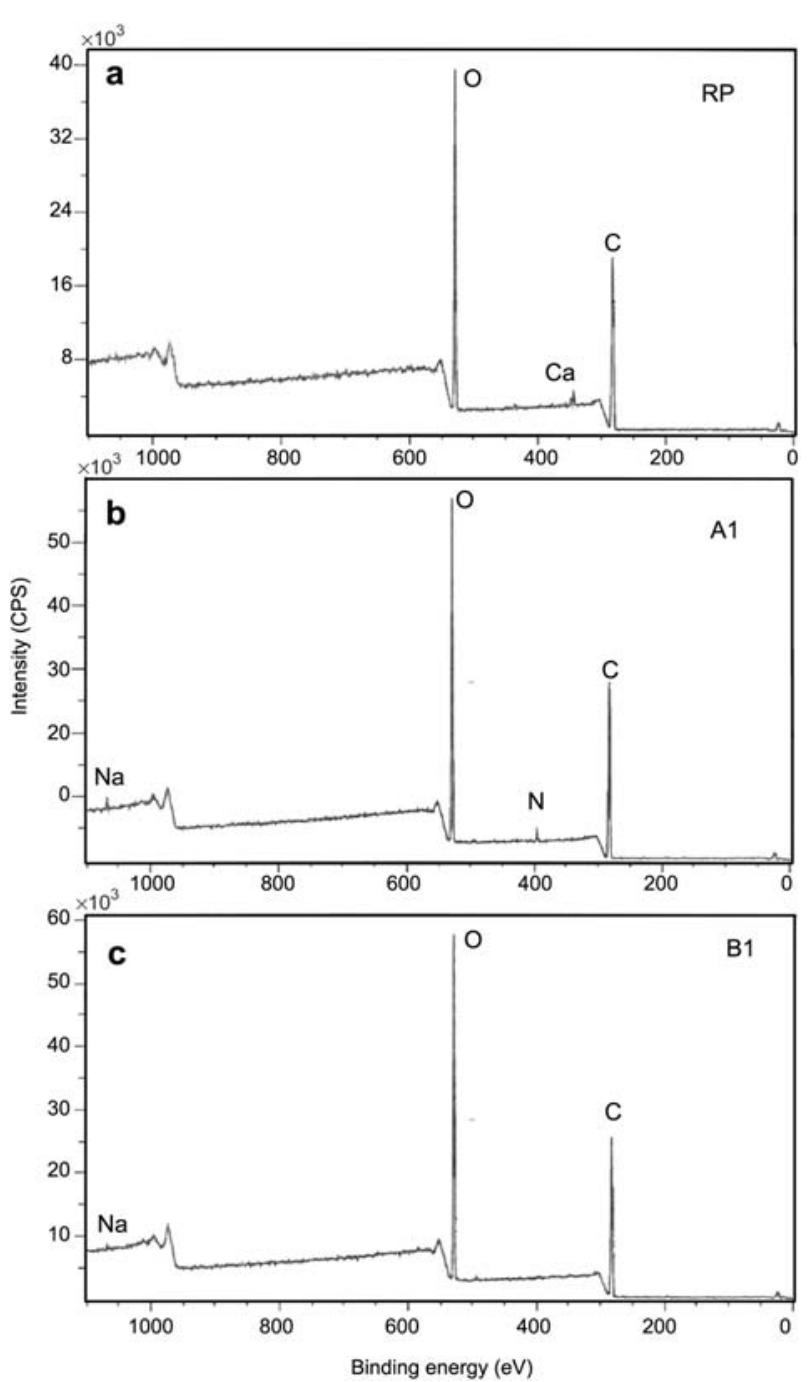

Figure 2 Spectra of the ESCA survey scans: (a) sample RP, (b) sample A1, (c) sample B1.

\section{Time-of-flight secondary ion mass spectrometry (ToF-SIMS)}

Both positive and negative ion ToF-SIMS spectra were recorded. To identify the most significant peaks corresponding to the sizing agents, subtraction of the RP spectrum was performed (Figure 5). The upper parts of each difference spectra show the peaks which are typical for the sized papers, while the peaks in the lower side represent the RP. Figure $5 a\left(\mathrm{~m} \mathrm{z}^{-1} 0-70\right.$, positive ion difference spectra), Figure $5 b\left(m z^{-1} 70-110\right.$, positive ion difference spectra), and Figure $5 c\left(\mathrm{~m} \mathrm{z}^{-1} 0-70\right.$, negative ion difference spectra) show the results for paper A1, while the corresponding difference spectra for paper B1 are presented in Figure $5 d-f$. The most relevant peaks are listed in Table 3. The difference spectra revealed more typical peaks than presented in Table 3 for both the starch and the acrylates, but the selected peaks are the most intense ones for the compounds and therefore they were evaluated. Sodium, calcium, cationic starch, and acrylate were evaluated from the positive mass spectra, whereas acrylonitrile was analyzed from the negative mass spectra.

The difference spectra in Figure 5 confirm that the surfaces of the samples exhibit distinct chemical character-
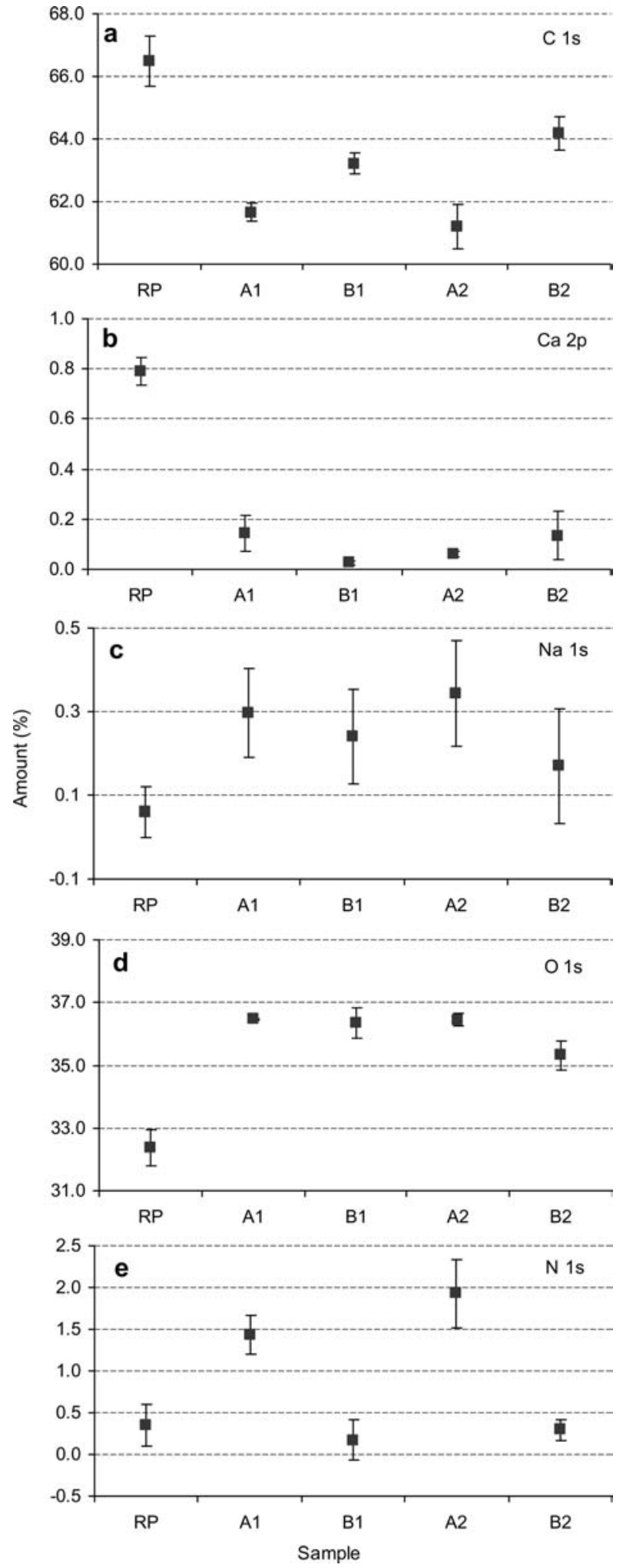

Figure 3 Relative amount of each element, obtained by ESCA for each sample: (a) carbon, (b) calcium, (c) oxygen, (d) sodium, (e) nitrogen.

istics. The surface characteristics of the sized papers clearly differ from those of the RP. Also, the differently sized papers clearly differ from each other having typical characteristics of their own in addition to their similarities, which originated from cationic starch and acrylate, both present in sized papers. According to Figure 5, the ref- 


\section{AUTHORS' PERSONAL DOCUMENT}
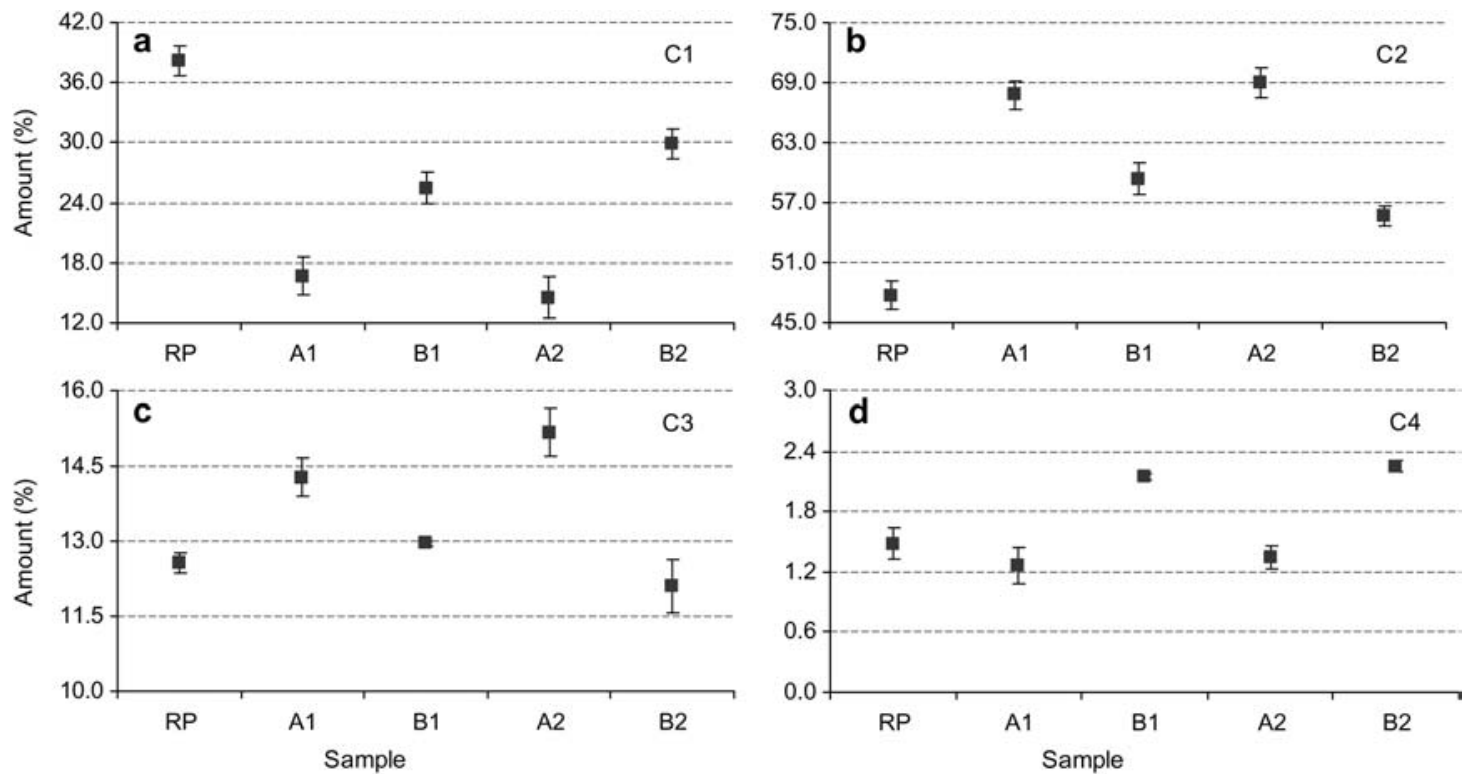

Figure 4 Quantification of the different types of chemical bonds detected by ESCA for the carbon atoms: (a) $\mathrm{C} 1(\mathrm{C}-\mathrm{C}, \mathrm{C}=\mathrm{C}, \mathrm{C}-\mathrm{H})$, (b) C2 (C-O), (c) C3 (C=O, O-C-O), (d) C4 $(\mathrm{O}-\mathrm{C}=\mathrm{O})$.
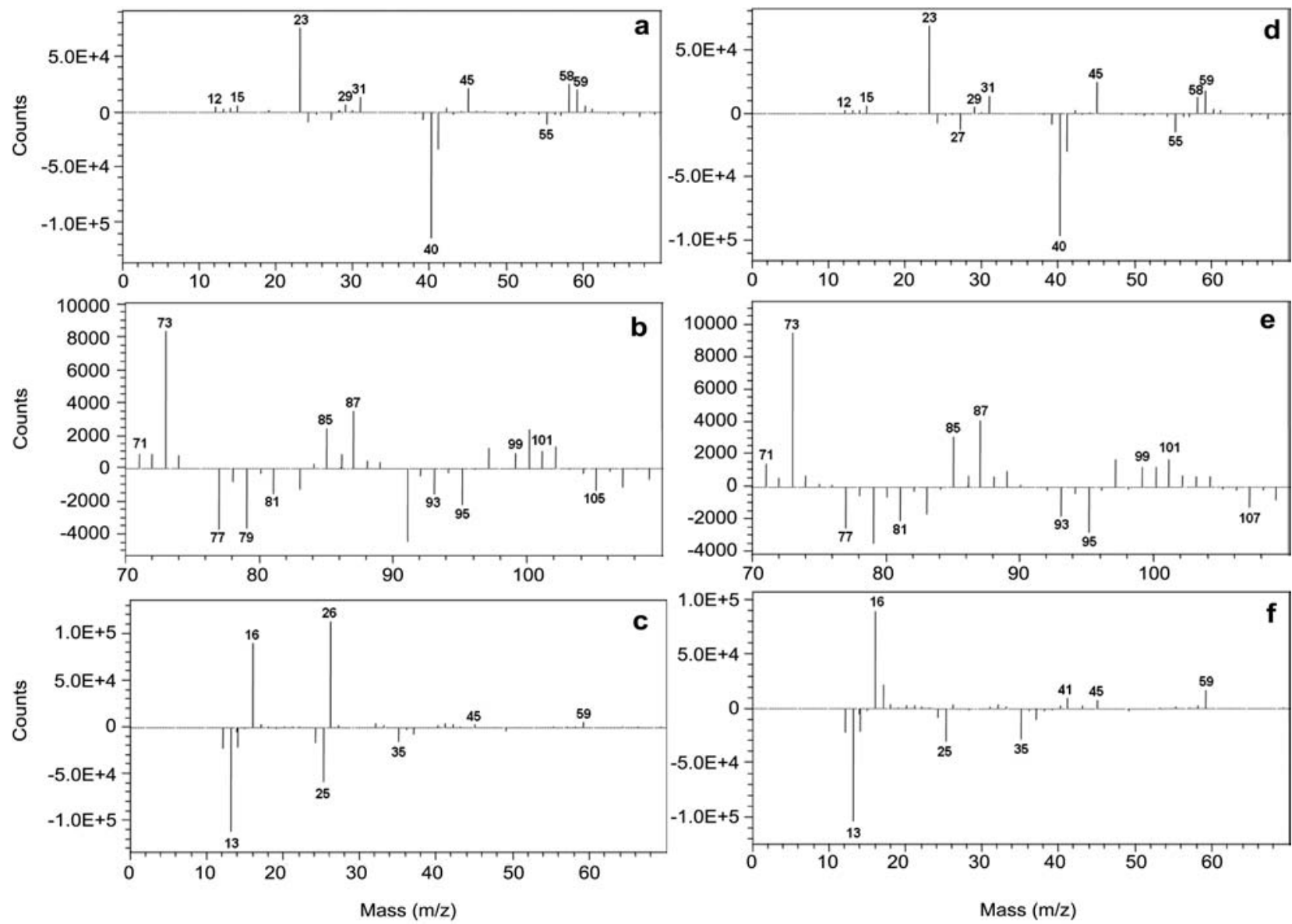

Figure 5 ToF-SIMS difference spectra between the sized paper A1 and the reference paper $(\mathrm{a}-\mathrm{c})$, as well as that between the sized paper B1 and the reference paper $(d-f)$.

erence paper contains more calcium (peak at $\mathrm{m} \mathrm{z}^{-1} 40$ ) than the sized papers, whereas the sized papers have more sodium (peak at $\mathrm{m} \mathrm{z}^{-1} 23$ ), cationic starch (peaks at $m z^{-1} 58$ and 59) (Matsushita et al. 2007), and acrylate (peaks at $\mathrm{m} \mathrm{z}^{-1} 71,73,85,87,99$, and 101) on their sur- faces. Since the difference spectra for samples $A 2$ and $\mathrm{B} 2$ were quite similar to the ones given for $\mathrm{A} 1$ and $\mathrm{B} 1$, respectively, they are not presented here. It should be mentioned that, according to some authors, the penetration of the cationic starch may be larger than the depth 
of analysis achieved by this technique (Lipponen et al. 2004; Lipponen 2005).

The difference spectra between the negative ion ToFSIMS spectra from the sized papers and the RP (Figure $5 c, f)$ indicate the presence of acrylonitrile (peak $\mathrm{m} \mathrm{z}^{-1} 26$ ) on the surface of $A 1$, but not on the surface of $B 1$ paper. Corresponding results were also observed for A2 and B2 samples. In addition, the results in Figure $5 \mathrm{c}$,f support the ESCA results (Figure $3 \mathrm{c}$ ) showing that there is more oxygen (peak $\mathrm{m} \mathrm{z}^{-1} 16$ ) on the surfaces of the sized papers than on the surface of the RP.

In an attempt to determine the relative quantity of each chemical specimen for each paper sample, the areas of the peaks in Table 3 were integrated from the original positive and negative ion ToF-SIMS spectra. The results, after combining the peaks according to their origin, are plotted in Figure 6. Accordingly, the reproducibility of the results is very good.

Similar to ESCA results (Figure 3), the RP exhibits a considerable amount of calcium, while only traces of it were found on all surface sized samples (Figure 6a). On the other hand, the amount of sodium is much higher in the sized papers (Figure 6b). These results also confirm that $\mathrm{NaCl}$ in the starch suspension is detectable at the surface. Only a slight increase in the surface concentration of sodium was observed when the amount of size was almost three-fold.

As expected, surface sized samples possess more starch at the surface than the RP (Figure 6c). Somewhat larger relative amounts of starch are detected on the surfaces of samples $A 1$ and $A 2$ in comparison to $B 1$ and B2. This is in agreement with the results from ESCA. Probably, the co-acrylonitrile-acrylate particles have penetrated the bulk of paper more easily than the co-styrene-acrylate particles. As discussed before, this is probably due to the surface tension values. Some increase in the surface concentration of starch was observed when the amount of size was almost three-fold.

The results further confirm the presence of acrylate in all the sizing formulations (Figure 6d). The amount of acrylate on the surfaces of $B$ samples is higher than in the A samples, probably due to its higher concentration in $B$ formulations. A large amount of acrylonitrile was found on the A sized papers, as expected. Paper A2 clearly had higher surface concentration of acrylonitrile

Table 3 Identification of the most important ion peaks and corresponding compounds detected by ToF-SIMS analysis on the surface sized samples.

\begin{tabular}{lcl}
\hline $\begin{array}{l}\text { Masses } \\
\left(m z^{-1}\right)\end{array}$ & Charge & \multicolumn{1}{c}{ Possible origin } \\
\hline 22.99 & + & $\mathrm{Na}-$ Salt in both sizing blends \\
39.96 & + & $\mathrm{Ca}-$ Base paper \\
58.07 & + & $\mathrm{C}_{3} \mathrm{H}_{8} \mathrm{~N}-$ Cationic starch \\
59.07 & + & $\mathrm{C}_{3} \mathrm{H}_{9} \mathrm{~N}-$ Cationic starch \\
71.01 & + & $\mathrm{C}_{3} \mathrm{H}_{3} \mathrm{O}_{2}-$ Acrylate $(1$ double bound) \\
73.03 & + & $\mathrm{C}_{3} \mathrm{H}_{5} \mathrm{O}_{2}-$ Acrylate \\
85.03 & + & $\mathrm{C}_{4} \mathrm{H}_{5} \mathrm{O}_{2}-$ Acrylate (1 double bound) \\
87.04 & + & $\mathrm{C}_{4} \mathrm{H}_{7} \mathrm{O}_{2}-$ Acrylate \\
99.04 & + & $\mathrm{C}_{5} \mathrm{H}_{7} \mathrm{O}_{2}-$ Acrylate (1 double bound) \\
101.06 & + & $\mathrm{C}_{5} \mathrm{H}_{9} \mathrm{O}_{2}-$ Acrylate \\
26.00 & - & $\mathrm{CN}_{-}$Acrylonitrile \\
\hline
\end{tabular}

than paper A1. Neither the RP nor the B sized papers contain acrylonitrile.

In general, the increase of the surface sizing pick-up from 3.5 to $9.0 \mathrm{~g} \mathrm{~m}^{-2}$ in both cases had a relatively low impact on the paper surface composition. The surface concentration of sodium and starch increased slightly, while that of acrylonitrile increased somewhat more. These effects were not observed with ESCA. ToF-SIMS is more sensitive in this regard compared to ESCA.

ToF-SIMS also provides additional information about the spatial distribution of surface compounds. Figure 7 presents the sodium images of the five samples analyzed

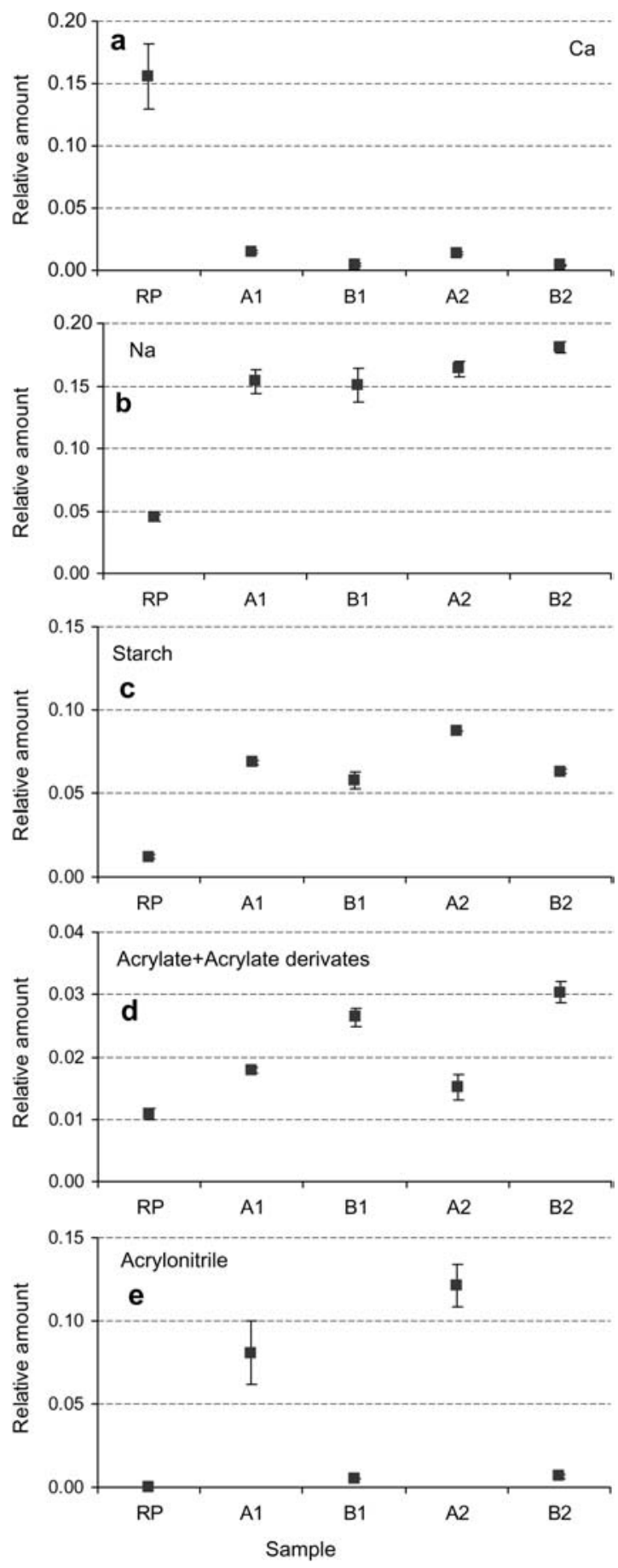

Figure 6 Relative amount of important surface specimens, obtained by ToF-SIMS (a) calcium, (b) sodium, (c) cationic starch, (d) acrylate, (e) acrylonitrile. 

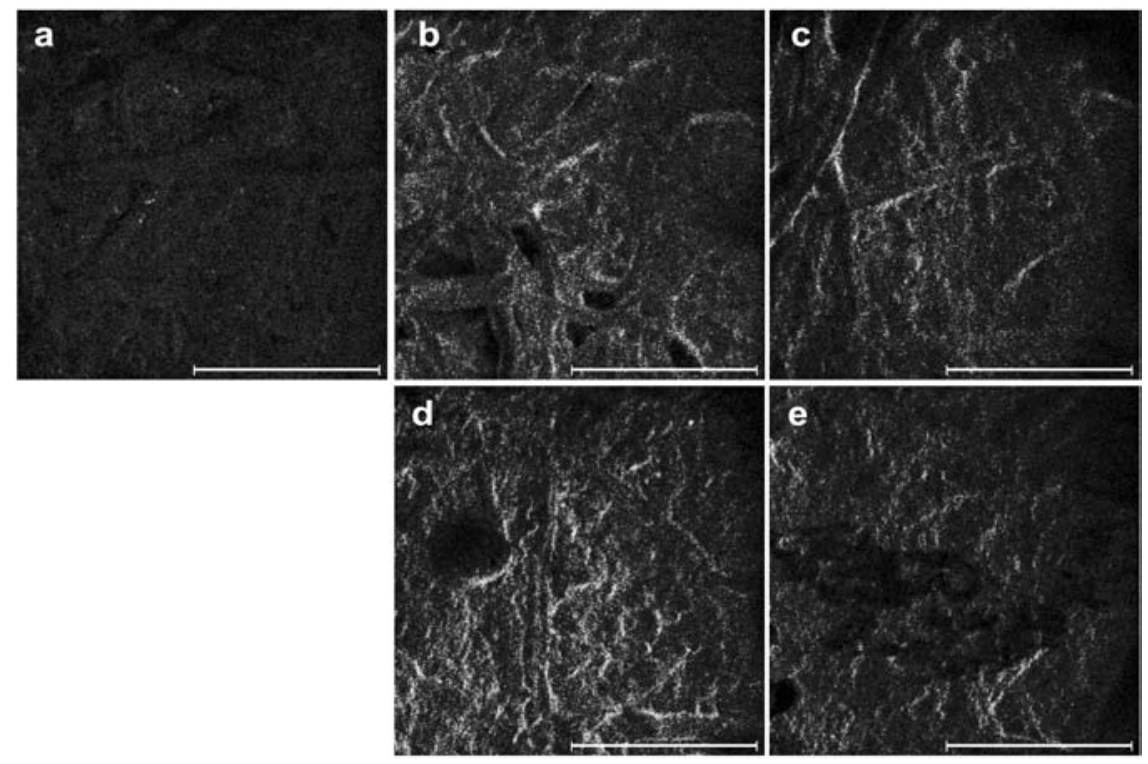

Figure 7 Calcium images of the various samples: (a) RP, (b) A1, (c) B1, (d) A2, (e) B2.

in this study. Sodium images were chosen since it was already proven that the sodium was from the sizing blends.

The larger area of white spots in Figure $7 \mathrm{~b}$ to e confirms the presence of the surface sizing in samples $A 1$, $A 2, B 1$, and B2. More sizing was found on A2 and B2 than on $A 1$ and $B 1$, respectively. Although distributed throughout the paper surfaces, the sizing formulation does not form a continuous film.

\section{Conclusions}

In this study, ESCA complemented with ToF-SIMS was proven to be a good method to evaluate the effect of different sizing formulations. The elements present at the sample surfaces were identified and their relative quantity could be evaluated. It was also possible to confirm that the sample surfaces exhibited distinct chemical characteristics. Although both formulations possessed the same percentage of cationic starch, relatively more of this polymer was detected on the sample surfaces, if coacrylonitrile-acrylate was applied. This result was interpreted in terms of the properties of copolymer particles. It is suggested that the co-acrylonitrile-acrylate particles penetrate deeper to the paper structure than the co-styrene-acrylate particles due to their lower surface tension and therefore leave behind relatively more starch at the paper surface. Additionally, it was found that the increase of the sizing pick-up from 3.5 to $9.0 \mathrm{~g} \mathrm{~m}^{-2}$ only slightly changed the surface characteristics. Accordingly, lower amount of size is enough for surface improvement.

\section{Acknowledgements}

The authors acknowledge the EU COST E32 Action "Characterization of Paper Surfaces for Improved Printing paper Grades" for the financial support to a Short Term Scientific Mission at the KCL Pulp and Paper Institute, Espoo, Finland and at the Åbo Akademi University, Turku, Finland.

\section{References}

Ajerschi, M., Poirier, N., Pikulik, I. (2004) Colagem superficial sem prensa de colagem - Resultados de máquina de papel piloto. O Papel/Paprican 47-58.

Brinen, J.S. (1993) The observation and distribution of organic additives on paper surfaces using surface spectroscopic techniques. Nordic Pulp Paper Res. J. 8:123-129.

Brinen, J.S., Proverb, R.J. (1991) SIMS imaging of paper surfaces. Part 2. Distribution of organic surfactants. Nordic Pulp Paper Res. J. 6:177-183.

Carceller, R., Juppo, A. (2004) New surface size composition changes paper surface properties for improving ink jet printability of copy paper. Pap. Puu-Pap. Tim. 86:161-163.

COST E32. (2002) Memorandum of understanding: characterisation of paper surfaces for improved printing paper grades. European Concerted Research Action COST Action E32, Brussels.

Donigian, D.W., Ishley, J.N., Wise, K.J. (1997) Coating pore structure and offset printed gloss. TAPPI J. 80:163-172.

Dorris, G.M., Gray, D. (1978) The surface analysis of paper and wood fibres by ESCA (electron spectroscopy for chemical analysis) application to cellulose and lignin. Cell Chem. Technol. 12:9-23.

Fardim, P., Holmbom, B. (2005a) Origin and surface distribution of anionic groups in different papermaking fibers. Coll. Surf. A 252:237-242.

Fardim, P., Holmbom, B. (2005b) ToF-SIMS imaging: a valuable chemical microscopy technique for paper and paper coatings. Appl. Surf. Sci. 249:393-407.

Forsström, U., Fagerholm, K., Saharenen, E. (2003) The role of base paper porosity in MSP coating. Pap. Puu-Pap. Tim. 85: 454-459.

Freire, C.S.R., Silvestre, A.J.D., Neto, C.P., Gandini, A., Fardim, P., Holmbom, B. (2006) Surface characterization by XPS, contact angle measurements and ToF-SIMS of cellulose fibers partially esterified with fatty acids. J. Coll. Interf. Sci. 301:205-209.

Hale, P.S., Kappen, P., Prissanaroon, W., Brack, N., Pigram, P.J., Liesegang, J. (2007) Minimizing silicone transfer during micro-contact printing. Appl. Surf. Sci. 253:3746-3750.

Hamers, C., Schatl, M., Krumbacher, E., Birkert, O., Fröhlich, U., Tietz, M., Gentisen, N. (2005) Curtain coating for graphic. Pulp Paper Intern. 47:36-37.

Hladnik, A. (2003) Ink-jet printing and image analysis. Presentation at Universidade da Beira Interior, Covilhã, Portugal. 
Johansson, L.S., Campbell, J.M., Fardim, P., Hultén, A.H., Boisvert, J.P., Ernstsson, M. (2005) An XPS round robin investigation on analysis of wood pulp fibers and filter paper. Surf. Sci. 584:126-132.

Kangas, H., Kleen, M. (2004) Surface chemical and morphological properties of mechanical pulp fines. Nordic Pulp Paper Res. J. 19:191-199.

Keskitalo, I. (2000) The penetration of water-based inks into laboratory sheets made from bleached eucalypt kraft pulp. Master's thesis, Luleå Tekniska Universitet, Sweden.

Kleen, M. (2000a) Surface chemistry of kraft pulp fibers during TCF bleaching studied by ToF-SIMS. In: 6th European Workshop on Lignocellulosics and Pulp (EWLP), September 3-6, 2000, Bordeaux, France. pp. 41-44.

Kleen, M. (2000b) ToF-SIMS as a new analytical tool for studies of pulp fiber surface chemistry. In: International Symposium on Cellulose and Lignocellulosics Chemistry 2000 (ISCLC), 16-18 December, 2000, Kunming, China. pp. 290-294.

Kleen, M. (2005) Surface lignin and extractives on hardwood RDH kraft pulp chemically characterized by ToF-SIMS. Holzforschung 59:481-487.

Kleen, M., Sjöberg, J., Dahlman, O., Johansson, L.-S., Koljonen, K., Stenius, P. (2002) The effect of ECF and TCF bleaching on the chemical composition of soda-anthraquinone and kraft pulp surfaces. Nordic Pulp Paper Res. J. 17:357-363.

Kleen, M., Kangas, H., Laine, C. (2003) Chemical characterization of mechanical pulp fines and fiber surface layers. Nordic Pulp Paper Res. J. 18:361-368.

Koskela, J.P., Hormi, O.E.O. (2003) Improving the printability of paper with long-chain quaternaries. APITTA J. 56:296-300.

Kristola, J. (2001) Spatial distribution of wood extractives and lignin on the surface of mechanical pulp, fibers and fines. Master of Science thesis, Laboratory of Forest Products Chemistry, Faculty of Chemical Engineering, Åbo Akademi University, Finland.

Laleg, M. (2004) Colagem superficial com quitosana e com misturas de quitosana e amidos. O Papel/Paprican 33-45.

Lee, T.G., Kim, J., Shon, H.K., Jung, D., Moon, D.W. (2006) Chemical derivatization technique in ToF-SIMS for quantification analysis of surface amine groups. Appl. Surf. Sci. 252: 6632-6635.

Lertsutthiwong, P., Nazhad, M.M., Chandrkrachang, S., Stevens, W.F. (2004) Chitosan as a surface sizing agent for offset printing paper. APITTA J. 57:274-280.
Lipponen, J. (2005) Surface sizing with starch solutions at high solids contents. Doctor's thesis, Laboratory of Paper Technology, Helsinki University of Technology, Espoo, Finland.

Lipponen, J., Lappalainen, T., Astola, J., Grön, J. (2004) Novel method for quantitative starch penetration analysis through iodine staining and image analysis of cross-sections of uncoated fine paper. Nordic Pulp Paper Res. J. 19:300-308.

Matsushita, Y., Sekiguchi, T., Saito, K., Kato, T., Imai, T., Fukushima, K. (2007) The characteristic fragment ions and visualization of cationic starches on pulp fiber using ToF-SIMS. Surf. Interf. Anal. 39:501-505.

Mešic, B., Järnström, L., Hjärthag, C., Lestelius, M. (2004) Effects of application temperature in paper surface sizing with temperature-responsive starch on water repellency and flexographic printability. APITTA J. 57:281-285, 298.

Moutinho, I.M.T., Ferreira, P.J.T., Figueiredo, M.M.L. (2007) Impact of surface sizing on inkjet printing quality. Ind. Eng. Chem. Res. 46:6183-6188.

Oliver, J., Chen, J., Tosto, F. (2001) Impact of paper surface structure on print quality. COST European E11 Meeting, 4-5 October, 2001, Espoo, Finland. pp. 1-9.

Parolis, L.A.S., van der Merwe, R., van Leerdam, G.C., Prins, F.E., Smeink, R.G. (2007) The use of ToF-SIMS and microflotation to assess the reversibility of binding of $\mathrm{CMC}$ onto talc. Minerals Eng. 20:970-978.

Pruszynski, P. (2003) Recent developments in papermaking chemicals. WWP Keynote Lectures 82-90.

Rutar, V., Hladnik, A. (2000) Penetration tests and influence of paper sheet structure on its sorption ability. Presented at the COST Action E11 Workshop, Grenoble, France.

Shchukarev, A.V., Mattsson, R., Ödberg, L. (2003) XPS imaging of surface diffusion of alkyl ketene dimer on paper surfaces. Coll. Surf. A 219:35-43.

Shirazi, M., Esmail, N., Garnier, G., van de Ven, T.G.M. (2003) Starch penetration into paper in a size press. In: Proceedings of the 5th International Paper and Coating Symposium, Montreal, Canada. pp. 63-71.

Ström, G., Carlsson, G., Schulz, A. (1993) Chemical composition of coated paper surfaces determined by means of ESCA. Nordic Pulp Paper Res. J. 1:105-112.

Received July 7, 2008. Accepted October 20, 2008.

Previously published online December 16, 2008. 